\title{
Correlation between ankle muscle strenght and the disturbs in foot posture
}

\author{
Ana Flávia Spadaccini Silva', Rodrigo Franco Oliveira', Joyce Karla Machado da Silva², Rinaldo Bernardelli Júnior², \\ Berlis Ribeiro dos Santos Menossi²
}

\begin{abstract}
Introduction: The ankle and foot are responsible for the support base of the whole body and variations in the foot posture influences the function of lower limbs. Objective: To observe whether there is a relationship between the isokinetic peak torque of ankle muscles with different types of foot. Method: The sample consisted of 32 volunteers, divided intentionally into 3 groups (normal, flat and cavus) according to the classification of the type of foot. They were evaluated in an isokinetic dynamometer Biodex 4 Medical Systems ${ }^{\circledR}$, for analysis of ankle muscles peak torque in flexion and dorsal plantar, inversion and eversion in concentric contraction at 30 and $60 \%$ speeds. Results: There was positive moderate correlation between cavus group and the inversion peak torque in the dominant lower limb and negative moderate correlation on the not dominant lower limb. The flat foot group presented correlation with peak torque in the plantar flexion movement at a speed of $30 \% \mathrm{~s}$ in non-dominant leg, which was negative moderate correlation. The normal foot group was correlated with peak torque of dorsiflexion movement in the dominant lower limb on $60 \%$ speed and the non-dominant leg on $30 \%$, been negative moderate correlations. Conclusion: The foot types were correlated with the ankle muscles, showing that alterations on the position of the feet, the ankle muscle strength changes depending on it.
\end{abstract}

KEYWORDS: dynamometer, muscle strength; muscle strength; posture.

\section{INTRODUCTION}

The ankle and foot, responsible for the base of support of the entire body ${ }^{(1)}$, and the cervical and cranial structures, responsible for the somatosensory cervical system, perform a special role in the management of muscular chains that respond to imbalances. ${ }^{(2)}$ According to Bricot ${ }^{(3)}$, the foot may be responsible for the postural imbalance that its pathology causes; to adjust to the imbalances coming from structures suprajacentes to it, being it a victim.

Menz and Morris ${ }^{(4)}$ claim that, in some cases, the distribution of plantar pressures influenced and changed itself according to the foot anatomy. For this, biomechanical studies have been important for identification and understanding of factors predisposing to changes in plantar pressure distribution.

Variations in the posture of the feet influence the function of the lower limbs. This, like most anthropometric characteristics, can vary considerably in children, adults and the elderly. Some variations are associated with changes in the movement and muscular activity of the lower limbs, and are strongly influenced by some systemic conditions, such as neurological and rheumatological alterations. These factors increase the fact that there are functional differences between the different types of feet. ${ }^{(5)}$

Foot posture measurements are considered an important musculoskeletal evaluation component in clinical practice and research, due to variations have shown influence in the lower limbs, gait, muscle activity, balance and functional ability.(6)

The exact quantification of muscle performance has always been a concern of health professionals. Isokinetic exercise is used as a method of assessing muscle strength that provides measurement of therapeutic efficacy and also helps to regain strength after injuries to the musculoskeletal system. One of the isokinetic exercise advantages on other types of exercise is that it makes it possible to evaluate the maximum potential muscle along the range of motion. ${ }^{(7)}$

In addition, electromechanical dynamometers provide resistance to joint movement over a given range, allowing the evaluation of parameters related to muscle strength

Corresponding Author: Ana Flávia Spadaccini Silva. Rua Tiradentes, 225 - Jardim Vesper - Andirá (PR), Brazil. +55 43 3538-5043/ +55 43 9914-2166. ana_spadaccini@ hotmail.com

1 Universidade Norte do Paraná (UNOPAR), Londrina (PR), Brazil

Full list of author information is available at the end of the article.

Financial support: Support Araucaria Foundation

Submission date 31 July 2016; Acceptance date 22 October 2016; Publication online date 10 November 2016 
dynamically. The resistance offered by the apparatus varies so that it is always equal to the force exerted by the individual. Thus, the dynamometer prevents the speed of movement exceeds the predetermined value and causes it to remain constant. In this evaluation, the peak torque is the point of maximum torque range of motion. ${ }^{(8,9)}$

Thus, in view of the changes and what may influence the feet posture, the objective of the study was to observe if there is a relation between the isokinetic torque peak of the ankle muscles with the different types of feet.

\section{METHOD}

The sample consisted of 33 women. Healthy volunteers were included, who had not practiced physical activity in the last 6 months and without musculoskeletal injuries in the last 3 months. A volunteer was excluded from the sample due to lack in the evaluation. Therefore, the sample resulted in 32 volunteers.

The study is characterized as a transversal study, of the quantitative type, which was approved by the Ethics Committee of the Universidade do Norte do Paraná, with number 411.044, via Plataforma Brasil. All evaluations were carried out in the Physical Evaluation Laboratory of the Universidade Estadual do Norte do Paraná - Health Sciences Center, by the same evaluator from April to May 2013.

The evaluation consisted of analysis of the type of the foot through the planting and evaluation of muscular strength in two speeds through an isokinetic dynamometer. All evaluations happened at the same time and day of the week. In the first week, foot type classification was performed, followed by the first isokinetic evaluation of the ankle in the movements of plantar flexion and dorsal flexion, in concentric contraction. After one week, the concentric isokinetic evaluation of the ankle was performed in the inversion and eversion movements. All evaluations started by the dominant lower limb, which was defined as the limb that had preference to kick.

From the plantigraphy analysis, the volunteers were intentionally divided into groups, according to the type of foot. For this, three groups were formed: Normal Foot Group (10 volunteers), Flat Foot Group (10 volunteers) and Concave Foot Group (12 volunteers).

For the assessment of foot type of voluntary, we used a plantígrado of Podaly ${ }^{\circledR}$ brand. During plantigraphy, it was asked to volunteer, barefoot and relaxed, stepped on one foot on the equipment surface and take a step forward, removing it then. ${ }^{(10-12)}$ The analysis addressed the following classification parameters: Cavus foot, when the individual has the width of the plantar impression of the midfoot smaller than $1 / 3$ of the ante-foot measurement. Normal foot when, the individual has the width of the plantar impression of the foot, corresponding to $1 / 3$ of the width of the plantar impression of the foot. Flat foot, corresponds to a foot that present in its footprint the width of the midfoot more than $1 / 3$ of the width of the forefoot. ${ }^{(13,14)}$

The isokinetic evaluation of the plantar flexor muscles, dorsal flexors, inverters and eversion in concentric contraction was performed at two speeds $(30 \% \mathrm{~s}$ and $60 \% \mathrm{~s})$ and was extracted peak torque (PT) in an isokinetic dynamometer of brand Biodex 4 Medical Systems ${ }^{\circledR}$, Biodex Multi-Joint System $4 P R O^{T M}$ model. Some procedures were adopted to guarantee the reliability of the data collection, such as the evaluator's experience in the application of the protocol, calibration of the isokinetic dynamometer, control of the ambient temperature always at 23 으, the same time for the evaluations and with a previous meal in a period more than two hours, do not present physical fatigue or signs of neurological impairment, physical and sensory deficits. The evaluation protocol consisted of 10-minute warm-up on the exercise bicycle at a speed of $20 \mathrm{~km} / \mathrm{h}$, familiarization with the device performed in 3 submaximal repetitions before the test itself, the isokinetic test composed of 5 concentric contractions in each speed $(30 \% \mathrm{~s}$ and $60 \% \mathrm{~s})$. The volunteer was fixed in the chair of the apparatus by 3 belts: 2 transverse in the chest and 1 in the abdomen. The seat backrest was held at 75 degrees in both tests. The dynamometer was positioned and adjusted according to the size of each volunteer.

Statistical analysis was performed in the Biostat 5.0 software, with the Shapiro Wilk tests for normality, Pearson correlation among the studied variables. Significance levels were adopted at $5 \%(p<0.05)$.

\section{RESULTS}

Data were analyzed and the results are expressed in tables 1,2 and 3.

There was correlation of the cavus foot group with the peak torque in the inversion movement in both the dominant lower limb and the non-dominant lower limb. These correlations were moderate, positive in the dominant limb and negative

Table 1. Correlation cavus foot with the peak isokinetic torque of ankle muscles in concentric contraction at speeds $30 \%$ s and $60^{\circ} / \mathrm{s}$.

\begin{tabular}{lccccc}
\hline & \multicolumn{2}{c}{$30^{\circ} / \mathrm{s}$} & & \multicolumn{2}{c}{$60^{\circ} / \mathrm{s}$} \\
\cline { 2 - 3 } \cline { 5 - 6 } & $p$ & $r$ & & $p$ & $r$ \\
\hline Plantar flexion D & 0.65 & -0.16 & & 0.47 & -0.25 \\
Plantar flexion ND & 0.84 & -0.07 & & 0.55 & -0.21 \\
Dorsal flexion D & 0.79 & -0.09 & & 0.13 & -0.30 \\
Dorsal flexion ND & 0.20 & -0.43 & & 0.57 & -0.20 \\
Inversion D & 0.16 & -0.48 & & $0.03^{*}$ & 0.68 \\
Inversion ND & 0.24 & -0.40 & & $0.02 *$ & -0.70 \\
Eversion D & 0.29 & -0.37 & 0.23 & -0.41 \\
Eversion ND & 0.16 & -0.47 & 0.46 & -0.26 \\
\hline
\end{tabular}

$\mathrm{D}=$ dominant; $\mathrm{ND}=$ non-dominant 
Table 2. Correlation of flat foot with the peak isokinetic torque of the ankle muscles in concentric contraction at speed of $30 \%$ and $60 \%$

\begin{tabular}{lllllll}
\hline & \multicolumn{3}{c}{$30^{\circ} / \mathrm{s}$} & & \multicolumn{3}{c}{$60^{\circ} / \mathrm{s}$} \\
\cline { 2 - 3 } \cline { 5 - 6 } \cline { 5 - 6 } & $p$ & & $r$ & & $p$ & $r$ \\
\hline Plantar flexion D & 0.12 & -0.52 & & 0.23 & -0.41 \\
Plantar flexion ND & $0.05^{*}$ & -0.60 & & 0.15 & -0.48 \\
Dorsal flexion D & 0.55 & -0.21 & & 0.73 & -0.12 \\
Dorsal flexion ND & 0.10 & -0.54 & & 0.11 & -0.53 \\
Inversion D & 0.27 & -0.38 & & 0.69 & -0.14 \\
Inversion ND & 0.38 & -0.31 & & 0.53 & -0.22 \\
Eversion D & 0.82 & -0.08 & & 0.88 & -0.05 \\
Eversion ND & 0.75 & -0.11 & & 0.85 & -0.06 \\
\hline
\end{tabular}

$\mathrm{D}=$ dominant; $\mathrm{ND}=$ non-dominant

Table 3. Correlation of the normal foot with the peak isokinetic torque of the ankle muscles in concentric contraction at speeds of $30 \% \mathrm{~s}$ and $60 \%$

\begin{tabular}{lllllll}
\hline & \multicolumn{3}{c}{$30^{\circ} / \mathrm{s}$} & & \multicolumn{3}{c}{$60^{\circ} / \mathrm{s}$} \\
\cline { 2 - 3 } \cline { 5 - 6 } \cline { 5 - 6 } & $p$ & & & & $p$ & $r$ \\
\hline Plantar flexion D & 0.09 & -0.56 & & 0.23 & -0.41 \\
Plantar flexion ND & 0.47 & -0.25 & & 0.11 & -0.52 \\
Dorsal flexion D & 0.11 & -0.53 & & $0.05^{*}$ & -0.61 \\
Dorsal flexion ND & $0.05^{*}$ & -0.62 & & 0.10 & -0.53 \\
Inversion D & 0.95 & 0.02 & & 0.25 & 0.39 \\
Inversion ND & 0.41 & 0.29 & & 0.37 & 0.31 \\
Eversion D & 0.81 & -0.08 & & 0.51 & 0.23 \\
Eversion ND & 0.21 & -0.43 & & 0.30 & -0.36 \\
\hline
\end{tabular}

$\mathrm{D}=$ dominant; $\mathrm{ND}=$ non-dominant

in the non-dominant lower limb, indicating an inversely proportional correlation.

The flat foot group showed a correlation with the peak torque of the plantar flexion movement at a velocity of $30 \%$ in the non-dominant lower limb, and this correlation was moderately negative.

The normal foot group showed a correlation with the peak torque of the dorsal flexion movement in the dominant limb at $60 \%$ s and in the non-dominant lower limb at $30 \%$ s, both of which were moderate and negative correlations.

\section{DISCUSSION}

The aim of this study was to observe if there is a relation between the peak of isokinetic torque of the ankle muscles with the different types of feet. Correlations were found in all groups, with variations in muscle groups.

In the study of Murley ${ }^{(15)}$ with 60 adults aged between 18 and 47 years, they were divided into groups: 30 adults with normal foot, 30 with flat foot. From the analysis with electromyography during gait, and the force test, performed with 3 maximum contractions against the resistance of the evaluator, in ankle movements, it was concluded that muscle function is affected by foot posture. As in the present study, it was possible to observe that, according to the foot posture, the muscular force in a movement is altered.

The strength of the dorsal and plantar flexors of the ankle have shown correlation with postural control and coordination of stability, fast walking, climbing stairs, sitting and standing and other functional movements. ${ }^{(16)}$ The flat foot and normal foot groups showed a correlation with the strength of the plantar and dorsal flexors, respectively, suggesting that functional movements may also present limitations in these groups.

The eversores showed no correlation with any of the foot types, which may have occurred due to fatigue due to the isokinetic test. The effects of fatigue can compromise the control of dynamic stabilizers of the ankle joint, i.e. the fibular muscles lose the ability to generate the eversor torque responsible for protecting the ankle-foot complex of the main mechanism of local injury, inversion associated with flexion planting. ${ }^{(17)}$

In addition, the inversion and eversion movements are combined movements, acting in synergy with other musculatures. For the accomplishment of these movements properly it is necessary familiarization with the instrument and exact coordination of the movement. Another factor limiting the evaluation of inverters and eversores is the determination of the range of motion and velocity established for the evaluation, these are similar to the natural movement of the joint, but are still not exactly the same as the functional movements.

The flat foot is characterized by partial or total collapse of the medial longitudinal arch. The weakness of their means of support may be related to muscle-ligament failure, especially the anterior tibial muscles and posterior and peroneus longus. ${ }^{(18)}$ In the present study, the flat foot showed a negative correlation with the plantar flexors, indicating that the how lower the strength of the plantar flexors, the flatter is the foot. The flat foot may have be congenital origin, resulting from some trauma, muscle weakness, ligamentous laxity, "fall" of the talar head, paralysis or a foot with deviation in pronation. ${ }^{(19)}$

The origin of a foot cavus may be in congenital problems, neurological problems or be caused by muscular imbalance, observing in this study the relationship of this particular type of foot with the investors. The tissues of the sole of the foot are abnormally short, which gives the foot shortened appearance. Often claw toes are due to the fall of the forefoot combined with the pull of the extensor tendons. ${ }^{(19)}$

The longitudinal arch is maintained by the tibialis anterior, posterior tibial, flexor digitorum longus, flexor hallucis longus, abductor hallucis and flexor digitorum brevis, the plantar fascia and the plantar ligament calcaneo navicular ${ }^{(14,20)}$ which act synergistically with muscles of the ankle, in the production of movement and joint stability. 
The foot system is an important tool in the control of posture and may be causative, adaptive or mixed, acting always, whatever the postural imbalance. ${ }^{(21)}$ In this study, only the variable strength was approached in relation to the alterations of the feet posture, however, they may affect the entire posture and the predisposition to injuries in the lower limbs. As described in the Neal study ${ }^{(22)}$, the pronation of the foot has been demonstrated as a risk factor for developing changes in the lower limbs, such as patellofemoral pain syndrome.

\section{CONCLUSIONS}

The foot types showed a correlation with the ankle muscles, showing that, according to the posture of the feet, the muscular strength changes as a function of itself.

In the cavus foot group, it was possible to observe that there was a correlation with peak torque in the inversion movement in both the dominant and the non-dominant lower limbs, which were moderate.

In the flat foot group, correlation was found with the peak torque of the plantar flexion movement at a velocity of $30 \%$ in the non-dominant lower limb, this is a negative correlation moderate, which indicates that the lower the strength of the plantar flexors, the breadth of the midfoot, making the foot flat.

The normal foot group showed a correlation with the peak torque of the dorsal flexion movement in the dominant $\operatorname{limb}$ at $60^{\circ} / \mathrm{s}$ in the non-dominant lower limb at $30^{\circ} / \mathrm{s}$, both of which were moderate and negative correlations, showing the importance of the work of this musculature to maintain normal postural alignment of the feet.

However, are necessary further studies and an association of more biomechanical variables that may influence the appearance of changes or that are influenced by the posture of the feet, since these can be causative or adaptive.

\section{AUTHOR'S CONTRIBUTIONS}

Silva AFS: Collection, data processing and writing; Oliveira RF: writing and correction; Silva JKM: Correction and supervision; Bernardelli Júnior R: Correction and supervision; Menossi BRS: data treatment, supervision and correction.

\section{CONFLICT OF INTEREST}

No conflicts of interest

\section{AUTHOR DETAILS}

${ }^{2}$ Universidade Estadual do Norte do Paraná (UENP), Jacarezinho (PR), Brazil.

\section{REFERENCES}

1. Kaya D, Doral MN, Nyland J, Toprak U, Turhan E, Donmez G, et al. Proprioception level after endoscopically guided percutaneous Achilles tendon. Knee Surg Sports Traumatol Arthrosc. 2013;21(6):1238-44.
2. Donatelli R, Dimond D, Holland M. Sport-Specific Biomechanics of Spinal Injuries in the Athlete (Throwing Athletes, Rotational Sports, and Contactcollision Sports). Clin Sports Med. 2012;31(3):381-96.

3. Bricot B. Posturologia Clínica, 1a edição, Ed. Cies Brasil, 2011.

4. Menz HB, Morris ME. Clinical determinants of plantar forces and pressures during walking in older people. Gait \& posture 2005;(21): 72-9.

5. Murley GS, Menz HB, Landorf KB. A protocol for classifying normal and flat-arched foot posture for research studies using clinical and radiographic measurements. Journal of Foot and Ankle Research 2009;(2):22.

6. Menz HB, Fotoohabadi MR, Wee E, et al. Visual categorisation of the arch index: a simplified measure of foot posture in older people. Journal of Foot and Ankle Research 2012;(5):10.

7. Oliveira SCG, Oliveira LM, Jones A, Natour J. Avaliação isocinética do tornozelo de pacientes com artrite reumatoide. Revista Brasileira de Reumatologia 2015;55(4):318-324.

8. Aquino CF. A Utilização da Dinamometria Isocinética nas Ciências do Esporte e Reabilitação. Revista brasileira de Ciência e Movimento 2007;15(1): 93-100.

9. Terreri ASAP. Avaliação isocinética no joelho do atleta. Revista Brasileira de Medicina do Esporte 2001;(7):2.

10. Cantalino JLR. Análise das impressões plantares emitidas por dois equipamentos distintos. ConScientiae Saúde 2008;7(3):367-372.

11. Bley AS, Ferraz G, Dias LV, Bacha IL. Confiabilidade entre plantigrafia e da linha de Feiss na avaliação do arco longitudinal medial do pé. ConScientiae Saúde 2011;10(3):508-513.

12. Cisneros LL, Fonseca THS, Abreu VCA. Confiabilidade intra e interexaminador da análise por padrões de impressão de plantigrafias de pessoas diabéticas obtidas com o Harris Mat, Revista Brasileira de Fisioterapia 2010;14(3).

13. Azevedo LA; Nascimento LFC. A distribuição da força plantar está associada aos diferentes tipos de pés? Rev Paul Pediatr 2009;27(3):309-14.

14. Barroco R, Viana S, Salomão O. Pé plano adquirido do adulto por disfunção do tendão tibial posterior. Sociedade Brasileira de Medicina e Cirurgia do pé. São Paulo - SP, 2003:199.

15. Murley GS, Menz HB, Landorf KB. Foot posture influences the electromyographic activity of selected lower limb muscles during gait. Journal of Foot and Ankle Research 2009, 2:35.

16. Spink MJ, Fotoohabadi MR, Wee E, Hill KD, Lord SR, Menz HB. Foot and Ankle Strength, Range of Motion, Posture, and Deformity Are Associated With Balance and Functional Ability in Older Adults. Arch Phys Med Rehabil 2011;92.

17. Rodrigues KA, Brazão JC, César BM, Ozaki EH, Almeida RS, Soares RJ et al. A fadiga influencia a resposta dos músculos eversores após a simulação de uma entorse do tornozelo? Revista Brasileira de Medicina do Esporte 2015;21(1).

18. Oliveira SCG, Oliveira LM, Jones A, Natour J. Avaliação isocinética do tornozelo de pacientescom artrite reumatoide. Rev Bras Reumatol. 2014.

19. Borges CS, Fernandes LFRM, Bertoncello D. Correlação entre alterações lombares e modificações no arco plantar em mulheres com dor lombar. Acta Ortop Bras. 2013;21(3):135-8.

20. Nicolopoulos CS, Scott BW, Giannoudis PV. Biomechanical basis of foot orthotic prescription. Curr Orthop. 2000;14(6):464-9.

21. Gomes RGR, Dias B, Souza I, Baptista AF, Mendes SMD, Coelho-Neto $\mathrm{JA}$, et al. Associação do Apoio Plantar com Desvios do Tronco no Plano Sagital. Revista de Pesquisa em Fisioterapia 2011, 1(1).

22. Neal BS, Griffiths IB, Dowling GJ, Murley GS, Munteanu SE, Smith $M M F$, et al. Foot posture as a risk factor for lower limb overuse injury: a systematic review and meta-analysis. Journal of Foot and Ankle Research 2014, 7:55. 